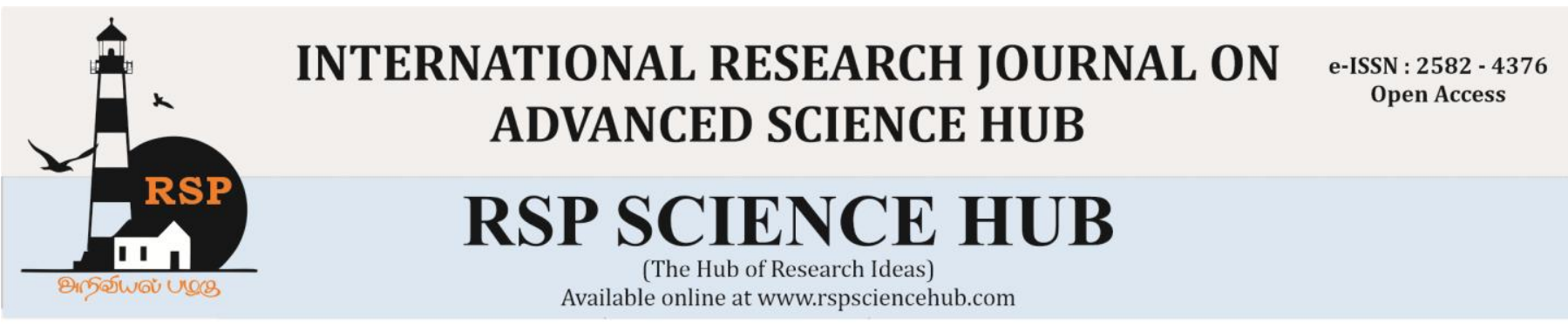

\title{
A Review on Applications of Superhydrophobic Coatings
}

\author{
Vipul Kumar Mishra ${ }^{1}$, Rahul Saini ${ }^{2}$, Naveen kumar ${ }^{3}$ \\ ${ }^{l}$ Department of Mechanical Engineering, ABES Engineering College, Ghaziabad, Uttar Pradesh, India. \\ ${ }^{2}$ Department of Mechanical Engineering, ABES Engineering College, Ghaziabad, Uttar Pradesh, India. \\ ${ }^{3}$ Department of Mechanical Engineering, ABES Engineering College, Ghaziabad, Uttar Pradesh, India. \\ rahul.saini@abes.ac.in ${ }^{2}$
}

\begin{abstract}
In this era of science where we want things to get more durable and affectless from outer element like corrosion, wear, water, friction, biofouling etc, in this which reduction of wettability is an important phenomenon. we try to mimic water repellence property from our nature to reduce contact with water like a lotus leaf, rose petal, cicada wings etc, this effect is known as superhydrophobicity. In this paper, we have discussed a general introduction about superhydrophobicity and will focus on its application in different fields. In this review paper, there are a lot of examples of coatings that are made by different researchers. We have discussed extensive area of application of superhydrophobicity like corrosion reduction, marine industries, aeroplane industry, self-cleaning, anti-icing, wear resistivity etc.
\end{abstract}

Keywords:Superhydrophobicity, Coatings, Contact angle, Corrosion, self-cleaning etc.

\section{Introduction}

In nature, we found a lot of examples of motivation for researchers to generate or mimic natural things in a scientific way. In this legacy we shaw property in nature like self-cleaning of lotus leaf, superhydrophobicity of rose petal, selfcleaning of cicada wings, the anti-biofouling property of fish scale etc [1]. So, in all these examples one thing is common that is superhydrophobic property. In general words, we can say that superhydrophobicity is a property of a surface that repels water on an extreme level and left the surface unwetted. On these surfaces, liquid or mainly water gets an almost spherical shape and doesn't get flat [2]. So how do they get in this shape? Actually, lotus leaf or rose petal or cicada wings are covered with some kind of waxy nanocrystal coating, this coating can be described by two different aspects that are surface chemistry and surface structure [3]. This waxy coating has nanostructured bumps in these nanostructured bumps air get trapped and due to this the water droplet doesn't get penetrate the crusts, so as a result, it minimizes the contact area of the water droplet and water contact angle increases. Due to increased contact angle water drop get the shape of a sphere. If This contact angle can become more than 150 degrees then it comes under superhydrophobicity. This superhydrophobic behaviour of lotus leaf led them to obtain properties like self-cleaning, anti-icing etc [4-7]. So, if researchers could make these types of coating on surfaces, we can get surface with the property of self-cleaning windshields, anti-icing panels, corrosion-resistant surface, wear resistance surfaces $[8,9]$. According to constructed contact angle on the surface, we can categorise the surface into hydrophilic, hydrophobic or superhydrophobic. So, if the water contact angle is less than 90 degrees then it will be categorised as a hydrophilic surface. If the contact angle is greater than 90 degrees then it is hydrophobic but when the water contact angle becomes greater than 150 degrees and water sliding angle i.e., tilted angle of the surface on which water slides down is less than 10 degrees can be referred to as super hydrophobic surfaces [10-12]. Last two and half decade researchers tried to mimic the super hydrophobic 
surface and used different materials to do so extensive review on the materials used and their properties are discussed further in this paper. During developing these surfaces researches get to understand the requirements for the super hydrophobic surface. The main requirements for super hydrophobic surface are-

1.1. Lower surface energy- Lower surface energy is a required parameter for superhydrophobicity. Some materials have lower surface energy but some surfaces don't have this property. Researchers have found and created some materials that can lower the surface of energy. Some surfactants like silane group steric acid, polymers are good reducing surfactants. In silane group fluoroalkyl silanes due to presence of $\mathrm{CF} 2$, CF3 group it shows the phenomenal property of energy reduction of surfaces. But due to the presence of fluorine researches are searching for an alternative to this compound [13-16].

\subsection{Surface roughness-}

It is essential for superhydrophobicity that the surface should be rough along with low surface energy. This rough surface trap air in between their valleys and control water from entering into them and it reduced the contacted surface area and water remains in sphere shape eventually glides on the surface. Practically no surface is absolutely plane surface all of them are rough, but for a better result in superhydrophobicity, we can control this roughness pattern on the surface and can increase water contact angle and lower the contacted surface area. There are different methods by which we can create surface roughness and control pattern i.e. etching [17], plasma method [18] etc [16,19,20]. As discussed, earlier contact angle should be greater than 150 degrees only then we can say that the surface is superhydrophobic, schematic diagram for the relation between contact angle and its property given in fig. here we can see the angle the contact angle is represented by $\theta_{\mathrm{Y}}$ and $\mathrm{S}, \mathrm{A}$ and $\mathrm{L}$ represent the solid, the air and the liquid phases, respectively.

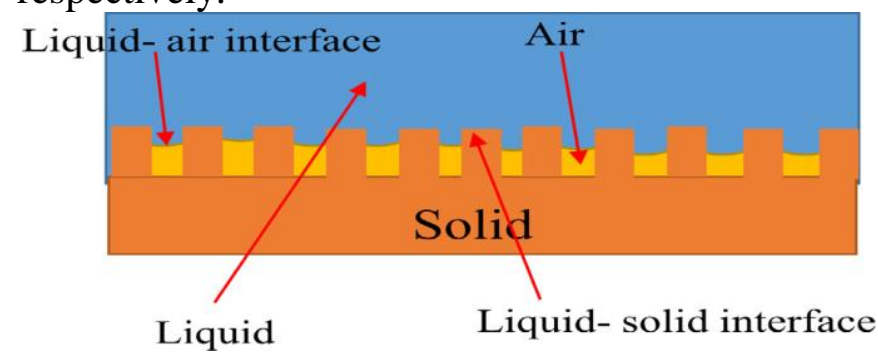

Fig.1 Rough surface and air trapping [16].

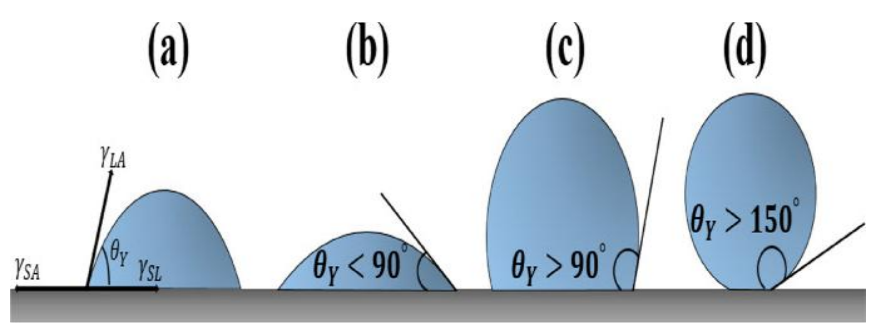

Fig.2 Contact angle.

a. Contact angle, b. hydrophilic surface, $c$. hydrophobic surface and d. superhydrophobic surface [14]

For superhydrophobicity, scientists have developed some wetting models by which we can calculate contact angle on the different surfaces. First in the $18^{\text {th }}$ century, Thomas Young published his model for measurement of contact angle on the plane surface [21]. Here is his formula

$\gamma_{\mathrm{LA}} \cdot \cos \theta_{\mathrm{Y}}=\gamma_{\mathrm{SA}}-\gamma_{\mathrm{SL}}$

After that Wenzel published his wetting model in 1936 for the rough surface on microstructured level surfaces, he introduced $\mathrm{R}$ that is a factor of roughness, his model was only for homogeneous surfaces [22]. Here is his formula

$\cos \theta_{\mathrm{W}}=\mathrm{R} \cos \theta_{\mathrm{Y}} \ldots$

$\mathrm{R}=$ Actual surface area/Planar surface

$\theta_{\mathrm{W}} \mathrm{Wenzle}$ contact angle

$\theta_{\text {Yis }}$ Youngs contact angle

Then Cassie-Baxter in 1944 gave their model on wettability for nanostructure heterogeneous surfaces [23]. Here is a formula

$\cos \theta_{\mathrm{CB}}=\mathrm{f}\left(\cos \theta_{\mathrm{W}}+1\right)-1$

$f=$ fraction of area which touches the water

$\theta_{\mathrm{CB}}=$ Cassie-Baxter contact angle
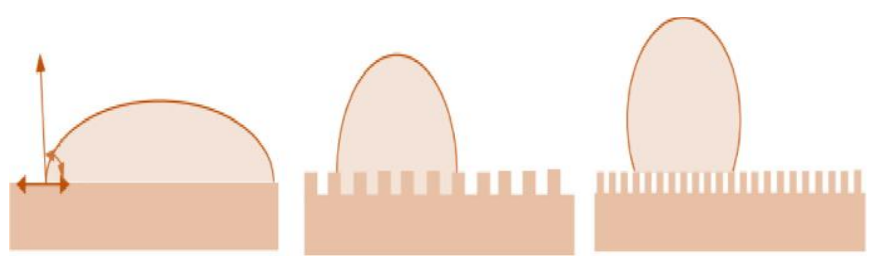

Fig. 3: Schematic photo of (a) Young's Model, (b) Wenzel Model, and (c) Cassie-Baxter Model [24]

These models are the basic model for wettability, many experiments are being done day by day to know more about wettability. Basically, we can make the surface superhydrophobic surface by 


\section{www.rspsciencehub.com}

going through some necessary changes and can also fabricate the surface with low energy material to enhance the superhydrophobic property. There are different ways we can fabricate surface like electrodeposition, sol-gel method [25], chemicalelectrochemical deposition [26], electrospinning [27] method etc.

\section{Applications}

In this section we will discuss the about the different application that is contained by superhydrophobic coatings. Due to the superhydrophobic layer, we can enhance different properties of the substrate, the self-cleaning property of the material is the main and wellknown application of the superhydrophobic layers. There are also other properties like non-fouling, anti-icing, also on the metal substrate they can increase the corrosion resistance, wear resistance, abrasion resistance properties in them. These properties can be created by the different types of superhydrophobic materials and their fabrication techniques. So here are some properties of superhydrophobicity.

\subsection{Self-Cleaning Property}

Self-cleaning is a property by which the material can clean itself by removing dirt, as we have discussed earlier the self-cleaning properties of secret lotus leave. This self-cleaning property is desired in different cases like in automobiles, selfcleaning of their windshields [28], this can also use in textiles industries to make waterproof clothes [29]. Some results are given by researchers to create better self-cleaning superhydrophobic layers. It was reported that a versatile coating that shows the property of self-cleaning and anti-glare was synthesised with a high contact angle of 168 degrees. These coatings were very stable even in outdoors conditions even up to $2000 \mathrm{hrs}$ of working [30]. With the help of Multiwall carbon nanotubes (MWCNT) mainly based on nanocomposites and thermoplastic stuff, $\mathrm{Li}$ et al. proclaimed that they made a superhydrophobic layer. These astute coatings are typically only prepared at shut conditions although not surface treatment of the substrate required. [31]. Qian and Cheng's researchers fabricated a micro/nanostructured $\mathrm{ZnO}$ alkylamine composite layer on carbon steel by electrodeposition and anodization process. The first electrodeposition process was completed then carbon steel was anodized with octadecylamine/ethanol. As a result, they found that it has good superhydrophobic property containing a water contact angle of 158 degrees on anodizing time of $60 \mathrm{~min}$. this low energy surface has a good self-cleaning property as it cleaned soil spread on the surface very easily, also it shows a good anti-adhesion property against pseudomonas aeruginosa bacteria in the aqueous environment [32].

(1)
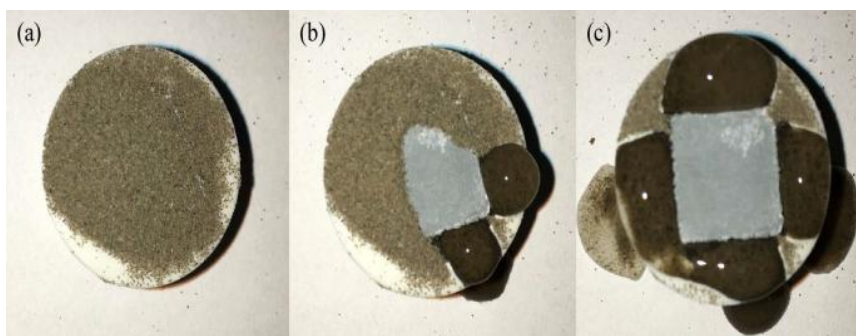

Fig 4. Self-Cleaning Property OfZnoAlkylamine Composite Layer Against Soil a) spread of soil on the surface, b) water droplet on the surface to clean, c) soil rolled away with water droplet from the surface [32].

Kim et al. used a two-step chemical etching process on stainless steel (AISI-304), first they etched the stainless-steel plate with Hydrofluoric acid and got a water contact angle of 166 degrees and sliding angle of 5 degrees and further to enhance superhydrophobicity they dipped the plate in $\mathrm{NaCl}$ solution at 100-degree Celcius, due to this water contact angle increased and became 168 degree and sliding angle became almost 2 degree. As a result, they found that it has very good selfcleaning property, contaminants get absorbed and get rolled with when coming in contact with water droplet, and also it has good durability as they check the water contact angle after 1 month and found that there was same water contact angle as before [33].

In another research, steel was fabricated with nickel by electrodeposition and a fluorinated approach was adopted. After altering different current densities, it found out that at the current density range from $5 \mathrm{~A} / \mathrm{dm} 2$ to $9 \mathrm{~A} / \mathrm{dm} 2$ surface get the highest contact angle i.e., more than 166 degrees and a sliding angle of 1 degree. This coating was durable till 400 days and it had excellent self-cleaning property [34]. He et al. proposed a durable superhydrophobic coating with recyclability and self-cleaning property with silica and polytetrafluoroethylene by drop coating method [35]. 


\subsection{Anti-Corrosion Property}

We have seen in our life that the transportation of natural gas, water etc is done with the help of pipelines. But natural gas contains many chemicals that have a very corrosive nature like $\mathrm{H} 2 \mathrm{~S}, \mathrm{CO} 2$ etc. So pipelines are always at risk of corrosion, erosion etc. It is generally believed that Superhydrophobic coatings can control the corrosion of the substrate. Due to coatings, the substrate got protected from the outer bad conditions and that's why due to superhydrophobic coatings the material get more life. In this, we will discuss the corrosive resistance coatings created by different scientists [36]. Wang et al. used a singlestage electrodeposition method and made a corrosion-controlled layer. He used zinc tetra decanoate film to electrodeposit on the substrate. He studied the corrosion resistance of the coating and as a result, he found out that the corrosion resistance of that coating was much greater than that of the substrate and so that this coating enhanced the corrosion resistance of the object [37]. In another experiment, zinc substrate was used and superhydrophobic coating of zinc- lauryl amine film was used and was deposited on the substrate by electrodeposition method. After that its property of corrosion was tested in a marine environment and found out that its corrosion resistance was increased significantly [38]. In an experiment, a stable SHS was produced on zinc substrate by immersion technique. Methanol solution of hydrolysed $1 \mathrm{H}, 1 \mathrm{H}, 2 \mathrm{H}, 2 \mathrm{H}-$ perfluorooctyltrichlorosilane was used as a solution in which zinc was immersed for 5 days, and after that, it was annealed by air at 135 degrees for 1 hour. This film provided a contact angle of 151 degree and shown good corrosion resistance properties for the zinc material [39]. Fan et al. created a superhydrophobic layer with the help of a surface energy reducer agent that was palmitic acid and used electrodeposition on carbon steel and created contact angle of 160.2 degrees, and done a corrosion resistance test and found out that corrosion current was decreased after the treatment of layer so that it was cleared that corrosion resistance property was increased [40]. Chen et al. used an aluminium coating to make SHS on steel by arc spraying technique. This was simple and could be used for large scale production. He created a contact angle of 151 degrees of the droplet. He used a polyurethane/nano-AL2O3 composite. The anticorrosive property of steel was enhanced and corrosion current density was reduced from $2.215 \times 10-3 \mathrm{Acm}-2$ to $1.873 \times 10-4$ Acm-2 [41]. Kwon et al. used a re-entrant structure to produce SHS on stainless steel. He used the laser ablation technique to etch the material initially, polishing and electrodeposition were done after that. With the help of laser ablation, micropillars were formed after that insulation take place then after mechanical polishing copper was electrodeposited on these structures (fig 5). This procedure obtains us the water contact angle of 153 degrees. He found that the water droplet was almost spherical and was in Cassie- Baxter state [42].

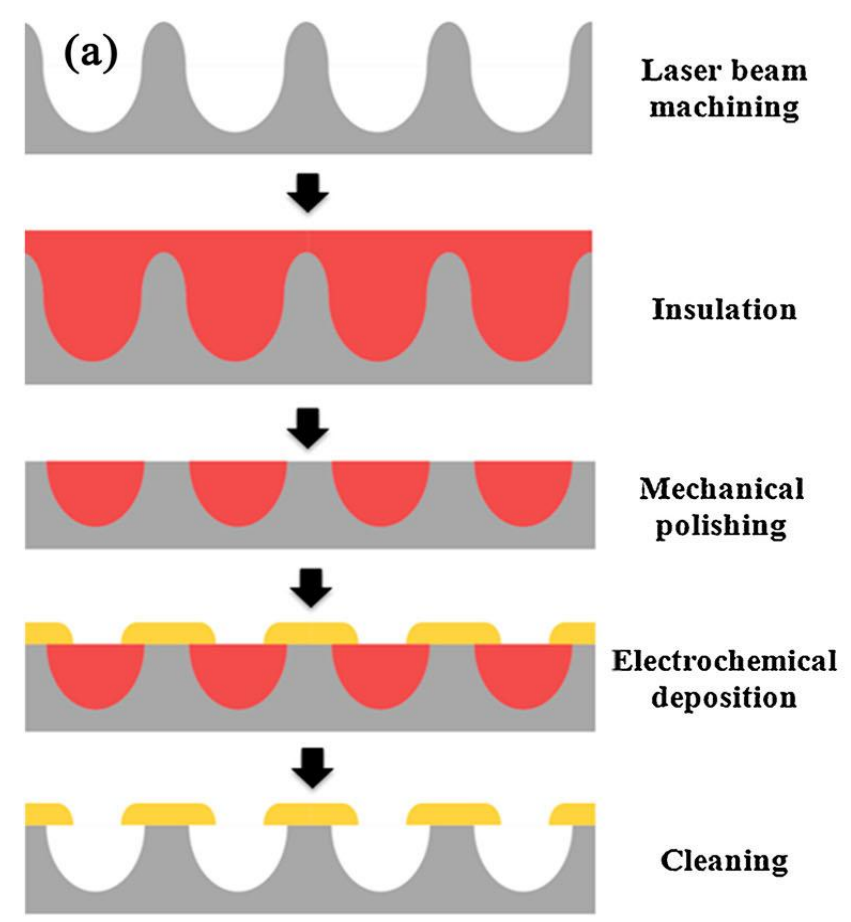

Substrate Insulating material Deposited material

Fig 5. Schematic diagram of a process [42]

Zhang et al. was used as a two-step coating to make SHS on stainless steel. First, he electrodeposited silica film which was hierarchically structured and after that he modified the surface with the help of silane to provide the superhydrophobicity. Due to this coating the corrosion resistance property, abrasion resistance property, and also thermal stability was increased [43]. With the help of nanosecond laser texturing and using fluoroalkyl silane (FAS-17), a circleshaped microstructure gets on the S45C steel. The water contact angle was 161.5 degree and it was showing corrosion resistance efficiency of $98.1 \%$, this leads that it shows good corrosion resistance and water repellency. And also, in case of damage 
of the top layer of SHS, it can regain its superhydrophobicity by re-modification, so it also shows good repairable property [44]. Ou et. al. conducts research on coating materials by two types of coating technique one is a hydrothermal process and another is chemical etching on different materials like aluminium, titanium, magnesium. They used Perfluoro octyltriethoxy silane (PFOTES) as their coating material. When they coated aluminium alloy, titanium and magnesium by the hydrothermal process they get a contact angle of 162,155,157 degrees, and when they perform chemical etching process on these materials respectively, they get $160,162,160$ degrees. All these coatings have a high corrosive property in nature [45]. Liu et al. produced a superhydrophobic surface with a contact angle of 151 degrees with the help of the solution immersion process. This fabricated surface act as a wall between water and oxygen so that they cannot get react with the base metal. This medium can reduce the rate of corrosion [46]. Salicio-Paz et. al. conducted their research on low carbon steel, they plated Nickel and phosphorus coating by an electroless coating method and the total plating time was 3 hours. They coated monolayer and multilayer (3 layers) and gave a comparative study. They show that the monolayer coating was very weak in comparison with the multilayer coating. They showed that due to annealed multilayer coating the delay in progress corrosion attack occurs and this blocks the advance of defect produced by the corrosive media [47]. Kuang et al. did a corrosion resistance study on magnesium substrate. They prepared biocompatible $\mathrm{Mg}-\mathrm{Mn}$ layer doubled hydroxide (LDH) film first on the pure magnesium through electric field-assisted immersion method, then this myristic acid and calcium chloride was electrodeposited on the prepared sample superhydrophobic layer get prepared. They got a 154.3-degree water contact angle and found that due to superhydrophobic coating there was a significant enhancement in corrosion resistance property [48]. In another experiment, Alghanab et al. used electroless Nickel-Phosphorus coating on AM60B magnesium alloy using layer double hydroxide (LDH) as under layer to enhance its corrosion resistance property. They take 2 to 8 hours of treatment time for preparation of LDH layer and found flake-like morphology. He found after 6 hours of immersion in $3.5 \mathrm{wt} \% \mathrm{NaCl}$ coating shows an excellent corrosion resistive property [49]. In study $17-4, \mathrm{PH}$ stainless steel is used as the substrate to fabricate a superhydrophobic layer for marine use by electrodeposition on $\mathrm{Zn}$ and by surface treatment with stearic acid. Adhesion durability and anticorrosion property were studied thoroughly and found that they got $155 \pm 1^{\circ}$-degree water contact angle and by salt spray corrosion testing they found that among different surface roughness best durability and anti-corrosion property obtain on surface roughness of $4.62 \pm 0.15 \mu \mathrm{m}$ [50]. A fluorine-free approach was used by Wang et al. to construct a superhydrophobic layer on mild steel for corrosion protection. They used a one-step electrodeposition process to coat dodecyltrimethoxysilane (DTMS) on mild steel. By potentiodynamic polarization technique, they found that mild steel gets an extensive increase in anticorrosion property when test with 3.5 wt. $\% \mathrm{NaCl}$ solution and the performance efficiency was found 99.72\% [51].

2.3. Anti-Icing Property- Nowadays icing has become the main problem is some industries like aircraft, ships, highways and telecom equipment etc. Due to this ice formation these industries face a huge loss. To remove ice from the equipment huge machine and a lot of energy is used. To overcome these problems scientists found that superhydrophobicity has the property that can neglect to ice or delay icing on the surface. Superhydrophobicity can also contain a slipping phenomenon alternative to anti-icing, in this formed ice get to slip off the surface, it reduces ice adhesion strength with the surface. The superhydrophobic surface which has an anti-icing property is called icephobic. Some of the results given by scientists for icephobic surfaces. In an experiment, it found that the surfaces which have high water repellency can prevent ice formation. The water droplet gets drop off from the surface before freezing on it. This can be said as the antiicing property. This same group also found that hierarchical structure can allow small water particle from the air (moisture) to condensed inside the microstructure and this can lose the purpose of anti-icing [52]. In a study, it found out that if the roughness will be in nano scaling then there can be a decrease of ice adhesion up to 15 times [53]. A polymeric superhydrophobic surface was made by Mobarakeh et al. which shows good anti-icing property. He used hexamethyldisiloxane coating by low-pressure plasma polymerization. This layer showed that it was icephobic even in the $15^{\text {th }}$ cycle of icing/de-icing, and also it shows that it has 3.5 
times lower ice adhesion on the surface [54]. Boinovich et al. used stainless steel as substrate and silica nanoparticles as fabricating material. They used the chemical etching and dispersion process. They get a contact angle of 155 degrees and a sliding angle of 42 degrees, this coating was good enough even after 100 cycles of icing and de-icing [55]. Cao et al. used a composite of acrylic polymer and silica nanoparticles as a coating material and glass as a substrate, they coat the film by polymerization process and get contact angle of 150 degrees and contact angle hysteresis less than 2 degrees, this surface had a great anti-icing property [56]. Liu et al. fabricated a superhydrophobic layer which has extensive anti-icing capabilities on the stainless steel AISI304 by two-step process first by chemical etching of stainless steel AISI304 with a mixture of ferric trichloride aqueous solution $(\mathrm{FeCl} 3,1.65 \mathrm{~mol} / \mathrm{L})$, hydrochloric acid $(\mathrm{HCl}, 37 \%)$ and hydrogen peroxide (H2O2, 30\%) (15:1:1, vol\%) for $20 \mathrm{~min}$ and after that modifying with DTS $(\mathrm{CH} 3(\mathrm{CH} 2) 11 \mathrm{Si}(\mathrm{OCH} 3) 3)$ and Toluene $(\mathrm{C} 6 \mathrm{H} 5 \mathrm{CH} 3)$ for $60 \mathrm{~min}$. as a result, they get to have an excellent anti-frosting property at a very low cost of approach [57]. In a research conducted for getting good icing-delay property on the substrate so they prepared multi-fluorination organic superhydrophobic coating by using a fluorinated resin matrix, perfluoro mercapto propionate hydrophobic agent and PTFE particles and they got water contact angle of 162 degree and good anti-abrasion wear property along with excellent icing delay ability even at -10 degree Celsius [58].

\subsection{Wear Resistance}

Slow elimination or deformation of material at a solid surface is called wear. There can be two main causes of wear mechanical erosion and chemical corrosion. In wear metal from the surface of the material detached in form of debris due to plastic displacement. The particle size may vary from millimetres to nanometres [59]. This wear needs to be controlled otherwise it can damage the material badly. We saw in some researches that the wear resistance of the material can increase by the superhydrophobic layer, some layers have the extensive property of wear resistance along with other properties. Some of the results have given by the researchers- Yizhou et al. prepared coating of TIO2/AL203 on $\alpha-\beta$ titanium alloy that has good corrosion property but poor wear property, then after coating by micro-arc deposition we found that its wear resistance properties get enhanced by 9.5 times [60]. Benea et al. studied the nanostructured $\mathrm{Ni} / \mathrm{SiC}$ composite coating by electroplating for the wear resistance and he found that the wear resistance of composite was more than only Nickel deposition [61]. Ramesh et al. used nickel-coated $\mathrm{SiC}$ reinforced with Al6061composite to coat the surface due to this reinforced composite there was an extensive change in wear resistance property, this composite reduces the coefficient of friction compared to uninformed composite. Due to the formation of oxides the coefficient of friction and wear resistance get significantly low [62]. With the help of polymerization and condensation and using coating material as quartz sad particles and organosilane on glass and cardboard researcher get a 158-degree contact angle and this coating has very good wear resistance properties [63]. Wear resistance study of superhydrophobic coating made of hydrophobic silica nanoparticles and acrylic resin matrix on a glass substrate or polished iron tin plate has done by Li et al., They found that when the coating was abraded with same roughness abrasive paper as that of superhydrophobic layer than it decays faster than if it abraded by more roughened abrasive paper and durability of hydrophobicity will be maintained [64]. By using cathodic arc evaporation method $\mathrm{Cr} / \mathrm{CrN}$ multimodule coatings deposition on the substrate HS6-5$2 \mathrm{C}$ steel. Seven $\mathrm{Cr} / \mathrm{CrN}$ modules of fixed thickness each, with various thicknesses of $\mathrm{Cr}$ and $\mathrm{CrN}$ layers, were deposited. Wear of coating, adhesion property, hardness was calculated. In these coatings in which the high content of pure $\mathrm{Cr}$ was there characterised as very good anti-wear properties [65]. In dental wires, we can see continuous wear due to different eatable items like peanuts, nougat chewing etc, even on brushing teeth. So, Lin et al. completed research to fabricate a superhydrophobic layer on stainless steel AISI304 by grid-blasting, plasma-polymerized and Vitro wear test was performed on it by creating artificial saliva and mimicking brushing, chewing etc. to determine its durability. As a result, they found that as tests time were increased the superhydrophobic capability of the layer get decreased but due to this layer durability of stainless steel as a medical purpose get increased [66].

\subsection{Anti-biofouling Property}

The interactions of solid surface structure with the biological environment have been studied a lot in recent years [67]. This phenomenon is undesirable for many processes. The accumulation of 
undesirable biofilms on the surface by microorganisms is called biofouling. There is two type of fouling take place one is due to biological colonisation and other is non-living particles. We can find a lot of ways by nature to control fouling by a chemical and physical mechanism like low drag less water wettability, micro-nano texturing and with help of other chemical excretions. Scientists generally mimic the ways of nature to control the fouling. The lessons learned from this can apply in engineering applications $[68,69]$. So, we can see from nature that the superhydrophobic layer by using a different physical and chemical process we can achieve anti-biofouling property in coated layer and can increase the life of the object. Different scientists have created SHS films for protection from biofoulings, some of them are shown below. We can see by the given figure about the area of susceptibility to biofouling and examples of anti-biofouling methods

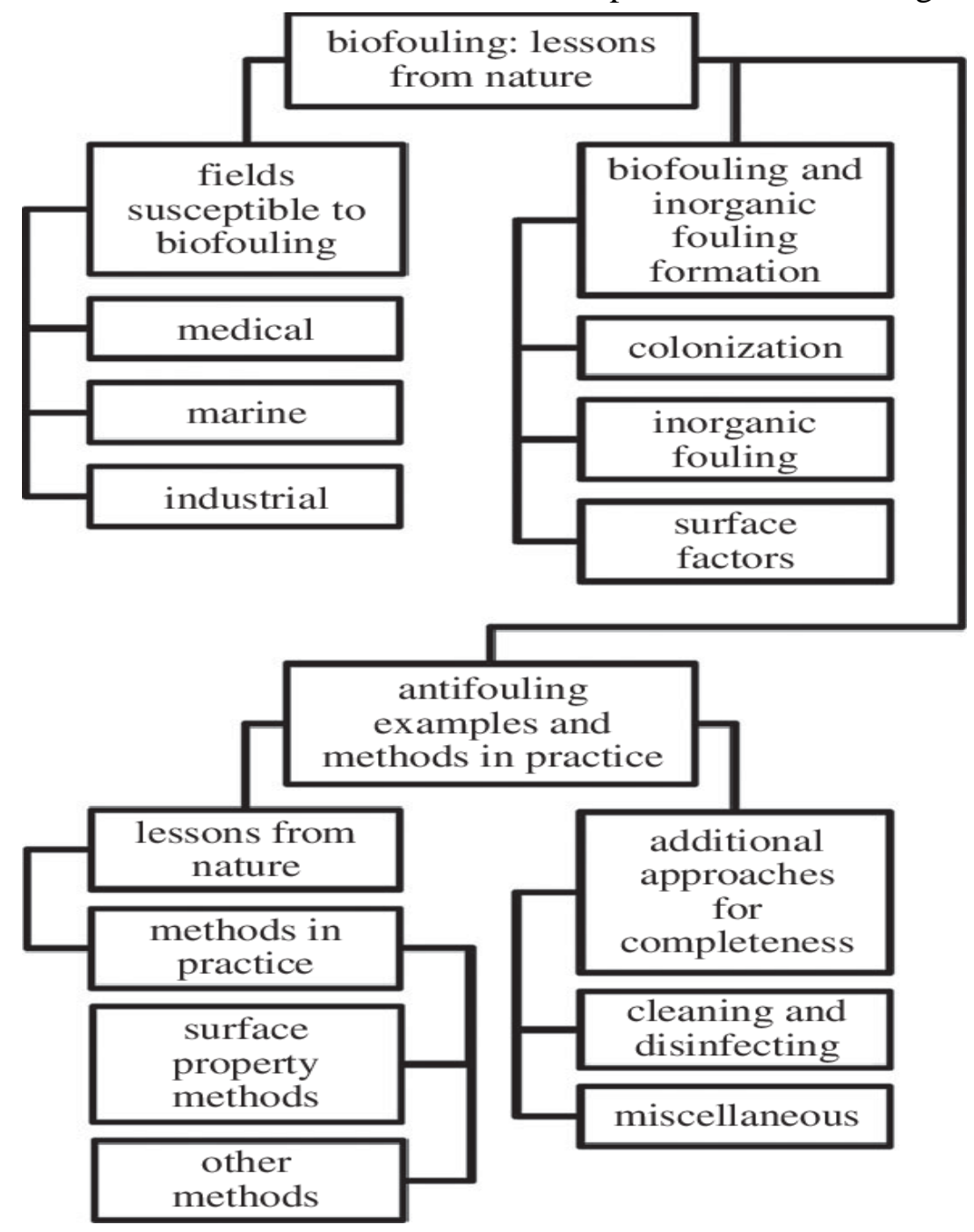

Fig 6. Susceptible fields for biofoulings and examples of anti-biofouling methods [68].

Common algae found on marines are generally green algae (Ulva australis) and brown algae (Ectocarpus) [70]. Due to the bio-fouling speed of ships get reduced due to extra drag which increases the fuel consumption [71]. Initially, anti-biofouling coatings films that were made on the marine ships were toxic that was ruining the marine environment so there was a need to use nontoxic coatings [72]. fluoropolymers and silicone elastomers can be used as nontoxic ecologically sound hydrophobic material and possess good self-cleaning property
[73]. Some racing boats use Silicon or siloxane elastomers because of their lower surface energy and less sticking hydrophobic surface, although these coatings can breakdown after some time [74]. Self-assemble monolayers (SAM) are used by heat exchangers because of their low surface energy hydrophobic property and low adhesion with bio fouls. SAM can also control the corrosion on the surface by controlling water and oxygen accumulation on the surface. SAM can hold against higher temperature like Silicon and hexadecyl can 
withstand up to 200 and 225 degree Celsius respectively [75]. Rahmawan et. al. shows with the help of a soft lithography process known as replica modelling, they produced a dual roughness hierarchical diamond-like carbon structure this structure was able to perform superhydrophobic as well as anti-biofouling property on the surface [76]. It is found that polymers degradation rate gets increased in the marine environment because of micro-organisms and enzymes. Butanolide which is a good anti-fouling agent, its degradation rate depends on both its initial concentration, temperature, generally, its release occurs in about three months. If we add natural resin in the biodegradable formulation then it can increase the release rate and self-renewability of butanolides. So biodegradable poly-e-caprolactone based polyurethane can also be used to make superhydrophobic layers [77]. Polyethylene glycol or oligoethylene glycol groups used to fabricate the superhydrophobic surface that can resist the protein and microbe's adhesion; however, they are less durable and frequent checking is required [78]. Sun et al. used stainless steel (AISI-304) for an antibiofouling study. He used picosecond laser to texture hierarchical micro, nanostructure on the substrate and put the substrate into seawater for 5 weeks to know the effect of biofouling, he found that there was 50 per cent less accumulation of microbe attachment area ratio than bare stainless steel. They found that interconnected microstructure attached with plentiful nanostructure is a very important aspect for antibiofouling superhydrophobic surfaces [79]. Selim et al. fabricated a superhydrophobic layer with the help of silicon ( $\mathrm{SiC}$ ) nanowire composite mainly for marine uses. the fouling realising properties of silicon nanocomposite was studied by immersing the sample in seawater for 3 months, due to low surface energy, contact angle 153 degree and micro/nanoscale roughness it has shown an excellent anti-biofouling property. This is an environmentally friendly solution for the fouling problem in marine uses [80]. Ni3S2 coating was fabricated on stainless steel by Yin et al., they used a combination of electrodeposition, chemical modification and solvothermal reaction. Due to the effects of nanorods morphology and low surface energy surface water droplets get bounced on the coated surface even at 300 degree Celsius. They get a water contact angle of 163 degree also a very effective biofouling contamination protection due to coating [81].

\subsection{Anti-Fogging Surface}

Fog is formed due to particles spread in the air. When vapour that is present in the atmosphere get condensed due to some temporary change of temperature, humidity or convection a fog is generated. So, if a fog is formed on a surface then this can scatter light and can reduce the optical clear view from the surface. So that anti-fogging surfaces is required in windshields, safety glasses, eyeglasses etc [82]. Antifogging is a common property of hydrophilicity and hydrophobicity with apparent contact angle [83]. In hydrophilicity when the contact angle is less than 40 degree then the fog generated on the surface gets condensed in skinny film and so that no fog is formed. On the other hand, when vapour is condensed and fog is generated on the superhydrophobic layer lower the fog formation by increasing the evaporation rate. Chen et al. proved it by fashioning fog on standard glass and superhydrophobic glass, the fog on standard glass try to make a water film and take much more time to evaporate on the other hand on the superhydrophobic glass due to multiplied area the fog disappeared in very less time. They also developed a superhydrophobic surface of water contact angle152 degree and with 8 degrees sliding angle by silica capsule particle by dip-coating method. This clear surface increased evaporation rate and fog get disappeared [84].

\section{Conclusion}

In this review paper we have discussed about superhydrophobicity by comparing it with some natural phenomenon and gave some important facts and requirements that are needed to generate hydrophobic property on the surface. We have discussed different wetting models and their formula for measuring water contact angle along with different applications of superhydrophobicity. We have discussed different applications like selfcleaning, anti-corrosion, anti-biofouling, antifogging, wear resistance etc with many examples of different researches work on these properties. These all properties have many applications in industries as well as daily life and innumerable fabrications have been made by researchers but plenty of them have been confined in labs only some of the techniques are on market. What is the reason for this? Actually, most of the techniques and material that were used by researches are very costly, time-taking and cannot be used for large fabrication. So, there is a need for researching this field for making it achievable to mass by making it 
cheaper and easy to fabricate. Also, there is a great challenge to make it more durable for use as these surfaces have to be used in outdoor conditions. Many testings have been done in laboratories but these fabrications have an actual use in outdoor condition. Also, this coating should be environment friendly so that there will be no harm to nature. So, these changes are necessary for this field to make it more useful to our daily life and industries.

\section{References}

[1] Koch, K.; Bhushan, B.; Barthlott, W. Multifunctional Surface Structures of Plants: An Inspiration for Biomimetics. Prog. Mater. Sci. 2009, 54, 137-178.

[2] Zhang X, Shi F, Niu J, Jiang Y, and Wang Z, Superhydrophobic surfaces: from structuralcontrol to functional application, Journal of Materials Chemistry, 2008, 18: 621633

[3] Ghasemlou, M.; Daver, F.; Ivanova, E. P.; Adhikari, B. Bio- Inspired Sustainable and Durable Superhydrophobic Materials: From Nature to Market. J. Mater. Chem. A 2019, 7, 16643-16670.

[4] Forbes, P, "Self-Cleaning Materials.' Sci. Am., 299 89-95 (2008)

[5] Bhushan, B, “Biomimetics: Lessons from Nature-An Overview.' Philos. Trans. R. Soc. A, 367 1445-1486 (2009)

[6] Boinovich, LB, "'Superhydrophobic Coatings as a New Class of Polyfunctional Materials.' Herald Russ. Acad. Sci., 83 (1) 8-18 (2013)

[7] Cheng, YT, Rodak, DE, "Is the Lotus Leaf Superhydrophobic?' Appl. Phys. Lett., 86 (144101) 1-3 (2005)

[8] Gould, P, “Smart, Clean Surfaces.' Mater. Today, 6 44-48 (2003)

[9] Liu, K, Jiang, L, "Bio-Inspired Self-Cleaning Surfaces." Bio-Inspir. Self-Clean. Surf., 42 231-263 (2012)

[10]Koch, K, Barthlott, W, 'Superhydrophobic and Superhydrophilic Plant Surfaces: An Inspiration for Biomimetic Materials.' Philos. Trans. R. Soc. A,2009, 367 1487-1509

[11] BalamuraliBalu, Jong Suk Kim, Victor Breedveld\& Dennis W. Hess (2009) Tunability of the Adhesion of Water Drops on a Superhydrophobic Paper Surface via Selective Plasma Etching, Journal of Adhesion Science and Technology, 23:2, 361380, DOI: $10.1163 / 156856108 X 383547$

[12] Jan Zimmermann, Georg R. J. Artus\& Stefan Seeger (2008) Superhydrophobic Silicone Nanofilament Coatings, Journal of Adhesion Science and Technology, 22:3-4, 251263, DOI: $10.1163 / 156856108 X 305165$

[13] Genzer, J., Efimenko, K., Recent developments in superhydrophobic surfaces and their relevance to marine fouling: a review. Biofouling 2006, 22 (5), 339-360.

[14] Mohammad Liravi1, Hossein Pakzad1, Ali Moosavi, Ali Nouri-Borujerdi, A comprehensive review on recent advances in superhydrophobic surfaces and their applications for drag reduction, Progress in Organic Coatings, 2020,140 105537.

[15] Kapil Manoharan1 and Shantanu Bhattacharya1, Superhydrophobic surfaces review: Functional application, fabrication techniques and limitations, Journal of Micromanufacturing 2019, 2(1) 59-78,

[16] BaratiDarband, G., Aliofkhazraei, M., Khorsand, S., Sokhanvar, S., \&Kaboli, A. (2018) Science and Engineering of Superhydrophobic Surfaces: Review of Corrosion Resistance, Chemical and Mechanical Stability. Arabian Journal of Chemistry.

[17] D. Choi, J. Yoo, S.M. Park, D.S. Kim, Facile and cost-effective fabrication of patternable superhydrophobic surfaces via salt dissolution assisted etching, Appl. Surf. Sci. 2017, 393 449-456.

[18] P. Dimitrakellis, E. Gogolides, Hydrophobic and superhydrophobic surfaces fabricated using atmospheric pressure cold plasma technology: a review, Adv. Colloid Interface Sci. 2018, 254 1-21.

[19] Onda, T., Shibuichi, S., Satoh, N., Tsujii, K.,Super-waterrepellent fractal surfaces. Langmuir1996, 12 (9), 2125-2127.

[20] Yao, L., He, J., Recent progress in antireflection and selfcleaning technologyFrom surface engineering to functional surfaces. Prog. Mater Sci. 2014, 61, 94-143.

[21] YoungT. 1805 Anessayon the cohesionof fluids. PhilosTrans. R Soc London.; 95:65-87. 
[22] Wenzel RN. Resistance of solid surfaces to wetting by water. Ind Eng Chem. 1936, 28:988-994.

[23] Cassie ABD, Baxter S. Wettability of porous surfaces. Trans Faraday Soc. 1944, 40,546551.

[24] Song, J, Rojas, OJ, “Approaching Superhydrophobicity from Cellulosic Materials: A Review.' Nord. Pulp Pap. Res. J.,2013, 28 (2) 216-238

[25] A.B. Gurav, S.S. Latthe, R.S. Vhatkar, Solgel-processed porous water-repellent silica microbowls, Surf. Innov. 1 2013, 157-161.

[26] Y. Yin, R. Huang, W. Zhang, M. Zhang, C. Wang, Superhydrophobic-superhydrophilic switchable wettability via $\mathrm{TiO}_{2}$ photoinductionelectrochemical deposition on cellulose substrate, Chem. Eng. J.2016,289 99105

[27] Li, X., Wang, C., Yang, Y., Wang, X., Zhu, M., \& Hsiao, B. S. Dual-Biomimetic Superhydrophobic Electrospun Polystyrene Nanofibrous Membranes for Membrane Distillation. ACS Applied Materials \& Interfaces, 2014, 6(4), 24232430. doi:10.1021/am4048128

[28] Quéré, D. Non-sticking drops. Reports on Progress in Physics 2005; 68(11), 24952532. doi:10.1088/0034-4885/68/11/r01

[29] Mahltig, B., \&Böttcher, H. Journal of Sol-Gel Science and Technology. 2003, 27(1), 43-52. doi:10.1023/a:1022627926243

[30] X.-T. Zhang, O. Sato, M. Taguchi, Y. Einaga, T. Murakami, A. Fujishima. Self-cleaning particle coating with antireflection properties, Chem. Mater. 2005, 17 (3) 696-700.

[31] Li, L., Bai, Y., Li, L., Wang, S., \& Zhang, T. A Superhydrophobic Smart Coating for Flexible and Wearable Sensing Electronics. Advanced Materials 2017, 29(43), 1702517. doi:10.1002/adma.201702517

[32] Shan Qian, Y. Frank Cheng. Fabrication of micro/nanostructured superhydrophobic $\mathrm{ZnO}-$ alkylamine composite films on steel for highperformance self-cleaning and antiadhesion of bacteria. Colloids and Surfaces A 2018, 544, $35-43$

[33] J-H. Kim, A. Mirzaei, H. Woo Kim, S. Sub Kim. Facile fabrication of superhydrophobic surfaces from austenitic stainless steel (AISI
304) by chemical etching, Applied Surface Science 2017, doi: https:// doi.org/10.1016/j.apsusc.2017.12.211

[34] J. Liang, D. Li, D. Wang, K. Liu, L. Chen. Preparation of Stable Superhydrophobic Film on Stainless Steel Substrate by a Combined Approach Using Electrodeposition and Fluorinated Modification, Applied Surface Science 2014 , http://dx.doi.org/10.1016/j.apsusc.2013.12.147

[35] Jinmei $\mathrm{He}, \mathrm{Yu}$ Zhao, Mingjuan Yuan, Lingang Hou, Ansar Abbas, MenghuiXue, Xuerui Ma, Jiao He, Mengnan Qu. Fabrication of durable polytetrafluoroethylene superhydrophobic materials with recyclable and self-cleaning properties on various substrates, J. Coat. Technol. Res. 2020, https://doi.org/10.1007/s11998-020-00322-7

[36] Ishizaki, T., Hieda, J., Saito, N., Saito, N., Takai, O. Corrosion resistance and chemical stability of super-hydrophobic film deposited on magnesium alloy AZ31 by microwave plasmaenhanced chemical vapour deposition. Electrochim. Acta 2010, 55 (23), 7094-7101.

[37] Wang, P., Zhang, D., Qiu, R., Hou, B. Superhydrophobic film prepared on zinc as a corrosion barrier. Corros. Sci. 2011, 53 (6) 2080-2086.

[38] Wang, P., Zhang, D., Qiu, R., Wu, J., Wan, Y. Superhydrophobic film prepared on zinc and its effect on corrosion in the simulated marine atmosphere. Corros. Sci. 2013, 69, 23-30.

[39] Liu, H., Szunerits, S., Xu, W., \&Boukherroub, R. Preparation of Superhydrophobic Coatings on Zinc as Effective Corrosion Barriers. ACS Applied Materials \& Interfaces 2009, 1(6), 11501153. doi:10.1021/am900100q

[40] Fan, Y., He, Y., Luo, P., Chen, X., Liu, B. A facile electrodeposition process to fabricate corrosion-resistant superhydrophobic surface on carbon steel. Appl. Surf. Sci. 2016; 368, 435-442.

[41] Chen X, Yuan J, Huang J. Large-scale fabrication of superhydrophobic polyurethane/nano-A12O3 coatings by suspension flame spraying for anti-corrosion applications. Appl Surf Sci. 2014, 311:864869. 
[42] Kwon MH, Shin HS, Chu CN. Fabrication of a super-hydrophobic surface on metal using laser ablation and electrodeposition. Appl Surf Sci. 2014, 288: 222-228.

[43] Zhang, X.F.; Chen, R.J.; Hu, J.M. Superhydrophobic surface constructed on electrodeposited silica films by two-step method for corrosion protection of mild steel. Corros. Sci. 2016, 104, 36-343.

[44] Ma Q., Tong Z., Wang W. Fabricating robust and repairable superhydrophobic surface on carbon steel by nanosecond laser texturing for corrosion protection. Appl Surf Sci. 2018, 455:748-757.

[45] Ou, J, Hu, W, Xue, M, Wang, F, Li, W. Superhydrophobic Surfaces on Light Alloy Substrates Fabricated by a Versatile Process and Their Corrosion Protection. ACS Appl. Mater. Interfaces 2013, 5 3101-3107

[46] Liu, H, Szunerits, S, Xu, W, Boukherroub, R. Preparation of Superhydrophobic Coatings on Zinc as Effective Corrosion Barriers. ACS Appl. Mater. Interfaces. 2009, 1 (6) 11501153

[47] A. Salicio-Paza, H. Grandea, E. Pellicerb, J. Sortb,c, J. Fornellb, R. Offoiachd, M. Lekkad, E. Garcia-Lecinaa. Monolayered versus multilayered electroless NiP coatings: Impact of the plating approach on the microstructure, mechanical and corrosion properties of the coatings, Surface \& Coatings Technology 2019, 368 138-146.

[48] Juan Kuang, Zhixin Ba, Zhuangzhuang Li, Zhangzhong Wang, JianhongQiu. The study on corrosion resistance of superhydrophobic coatings on magnesium, Applied Surface Science 2019, doi: https://doi.org/10.1016/j.apsusc. 2019.144137

[49] K. Abdi-Alghanab, D. Seifzadeh, Z. Rajabalizadeh. High corrosion protection performance of the LDH/Ni-P composite coating on AM60B magnesium alloy, Surface \& Coatings Technology 2020, https://doi.org/10.1016/j.surfcoat.2020.125979

[50] Amiriafshar, M., Rafieazad, M., Duan, X., \&Nasiri, A. Fabrication and Coating Adhesion Study of Superhydrophobic Stainless Steel Surfaces: the Effect of Substrate Surface Roughness. Surfaces and Interfaces 2020, 100526. doi:10.1016/j.surfin.2020.100526
[51] Chen-Xiang Wang, Xue-Fen Zhang. A nonparticle and fluorine-free superhydrophobic surface based on one-step electrodeposition of dodecyltrimethoxysilane on mild steel for corrosion protection, Corrosion Science 2019, https://doi.org/10.1016/j.corsci.2019.108284

[52] Wang Y, Liu J, Li M, Wang Q, Chen Q. The icephobicity comparison of polysiloxane modified hydrophobic and superhydrophobic surfaces under condensing environments. Applied Surface Science 2016, 385:472-80.

[53] Bengaluru Subramanyam S, Kondrashov V, Ruhe J, Varanasi KK. Low Ice Adhesion on Nano-Textured Superhydrophobic Surfaces under Supersaturated Conditions. ACS Appl Mater Interfaces. 2016, 8,12583-7.

[54] Foroughi Mobarakeh L, Jafari R, Farzaneh M. The ice repellency of plasma polymerized hexamethyldisiloxane coating. Applied Surface Science. 2013, 284,459-63.

[55] Boinovich, LB, Emelyanenko, AM, Ivanov, VK, Pashinin, AS. Durable Icephobic Coating for Stainless Steel. ACS Appl. Mater. Interfaces 2013, 5 2549-2554

[56] Cao, L, Jones, AK, Sikka, VK, Wu, J, Gao, D. Anti-icing Superhydrophobic Coatings. Langmuir 2009, 25 (21) 12444- 12448

[57] Yan Liu, Yuan Bai, JingfuJin, Limei Tian, Zhiwu Han, Luquan Ren. Facile fabrication of biomimetic superhydrophobic surface with anti-frosting on stainless steel substrate, Applied Surface Science 2015, 355, 12381244.

[58] YibinLiua,b, Kang Fub, JinLiub, Yi Tianb, Hao Zhangb, RuminWangb, BaoliangZhanga,b, HepengZhanga,b, FengtaoZhoub, QiuyuZhanga,b. Design and preparation of a multi-fluorination organic superhydrophobic coating with high mechanical robustness and icing delay ability, Applied Surface Science 2019, 497, 143663

[59] Akchurin, Aydar, Bosman, Rob, Lugt, Piet M., Drogen, Mark van. Analysis of Wear Particles Formed in Boundary-Lubricated Sliding Contacts. Tribology Letters. 2016-0616; 63(2): 16. doi:10.1007/s 11249-016-0701-z

[60] Shen Yizhou, Tao Haijun, Lin Yuebin, Zeng Xiaofei, Wang Tao, Tao Jie, Pan Lei. Fabrication and Wear Resistance of TiO2/Al2O3 Coatings by Micro-arc Oxidation. 
Rare Metal Materials and Engineering 2017, 46(1): 0023-0027.

[61]Benea, L., Bonora, P. L., Borello, A., \&Martelli, S. Wear corrosion properties of nano-structured SiC-nickel composite coatings obtained by electroplating. Wear 2001, 249(1011), 995-1003. doi:10.1016/s00431648(01)00844-4

[62] Ramesh, C. S., Keshavamurthy, R., Channabasappa, B. H., \& Pramod, S. Friction and wear behavior of Ni-P coated Si3N4 reinforced Al6061 composites. Tribology International 2010,43(3), 623634. doi:10.1016/j.triboint.2009.09.011

[63] Qu, M., Liu, S., He, J., Feng, J., Yao, Y., Hou, L., \& Ma, X. Bioinspired durable superhydrophobic materials with antiwear property fabricated from quartz sands and organosilane. Journal of Materials Science 2016, 51(18), 8718-8727.

[64] Meng Li, Yu Li, Fang Xue, Xinli Jing. A robust and versatile superhydrophobic coating: Wear-resistance study upon sandpaper abrasion, Applied Surface Science 2019, 480 738-748.

[65] Szparaga, Ł., Mydłowska, K., Gilewicz, A. and Ratajski, J. Mechanical and anti-wear properties of multi-module $\mathrm{Cr} / \mathrm{CrN}$ coatings. Int. J. Surface Scienceand Engineering, 2019, 13(1),37-49.

[66] Cheng-Wei Lin, Chi-Jen Chung, Chia-Man Chou, Ju-Liang Hea, In vitro wear tests of the dual-layer grid blasting-plasma polymerized superhydrophobic coatings on stainless steel orthodontic substrates, Thin Solid Films 2019, 687, 137464

[67] YudiRahmawan, Kyung-Jin Jang, MyoungWoon Moon, Kwang-Ryeol Lee \&Kahp-Yang Suh. Anti-biofouling Coating by Wrinkled, Dual-roughness Structures of Diamond-like Carbon (DLC) Biochip Journal 2009, Vol. 3, No. 2, 143-150

[68] Gregory D. Bixler And Bharat Bhushan. Biofouling: lessons from nature. Phil. Trans. R. Soc. A 2011, 370, 2381-2417 doi:10.1098/rsta.2011.0502

[69] Melo, L. F., Bott, T. R. \& Bernardo, C. A. Fouling science and technology. Dordrecht 1988, The Netherlands: Kluwer Academic Publishers.
[70] Callow, M. E. A world-wide survey of slime formation on anti-fouling paints. In Algal biofouling (eds L. V. Evans \& K. D. Hoagland), pp. 1-20. 1986, Amsterdam, The Netherlands: Elsevier Science Publishers.

[71] Jones, G. The battle against marine biofouling: a historical review. In Advances in marine antifouling coatings and technologies (eds C. Hellio\& D. Yebra), pp. 19-45. 2009, Boca Raton, FL: CRC Press.

[72] Fingerman, M., Nagabhushanam, R. \& Thompson, M. F. Recent advances in marine biotechnology. Enfield 1999, NH: Science Publishers, Inc.

[73] Clarkson, N. The antifouling potential of silicone elastomer polymers. In Recent advances in marine biotechnology (eds $\mathrm{M}$. Fingerman, R. Nagabhushanam\& M. F. Thompson), pp. 87-108. 1999, Enfield, NH: Science Publishers.

[74] Vladkova, T. Surface engineering for nontoxic biofouling control. J. Univ. Chem. Technol. Metallurgy 2007, 43, 239-256.

[75] Venkatesan, R. \& Murthy, P. S. Macrofouling control in power plants. In Springer series on biofilms (ed. J. W. Costerton), pp. 265-290. 2008; Berlin, Germany: Springer-Verlag.

[76] YudiRahmawan, Kyung-Jin Jang, MyoungWoon Moon, Kwang-Ryeol Lee \&Kahp-Yang Suh. Anti-biofouling Coating by Wrinkled, Dual-roughness Structures of Diamond-like Carbon (DLC) Biochip Journal 2009; Vol. 3, No. 2, 143-150

[77] M.S. Selim, M.A. Shenashen, S.A. El-Safty, S.A. Higazy, M.M. Selim, H. Isago, A. Elmarakbi. Recent progress in marine foulrelease polymeric nanocomposite coatings, Prog. Mater. Sci. 2017, 87 1-32.

[78] Banerjee, I, Pangule, RC, Kane, RS. Antifouling Coatings: Recent Developments in the Design of Surfaces That Prevent Fouling by Proteins, Bacteria, and Marine Organisms. Adv. Mater. 2011, 23 690-718

[79] Ke Sun, Huan Yang, Wei Xue, An He, Dehua Zhu, Wenwen Liu, Kenneth Adeyemi, Yu Cao. Anti-biofouling superhydrophobic surface fabricated by picosecond laser texturing of stainless steel, Applied Surface Science 2018, 436, 263-26 
[80] Mohamed S. Selim, Hui Yang, Feng Q. Wang, Nesreen A. Fatthallah, Xue Li, Yue Li, Yong Huang. Superhydrophobic silicone/SiC nanowire composite as a fouling release coating material, J. Coat. Technol. Res. 2019, https://doi.org/10.1007/s11998-019-00192-8

[81] Xiaoli Yin, Sirong Yu, Kang Wang, Ruichen Cheng, Zhexin Lv. Fluorine-free preparation of self-healing and anti-fouling superhydrophobic Ni3S2 coating on 304 stainless steel, Chemical Engineering Journal 2020, 394,124925

[82] Howarter, JA, Youngblood, JP. Self-Cleaning and Next Generation Anti-fog Surfaces and Coatings. Macromol. Rapid Commun. 2008, 29 455-466

[83] Lai, Y, Tang, Y, Gong, J, Gong, D, Chi, L, Lin, C, Chen, Z. Transparent Superhydrophobic/Superhydrophilic TiO2Based Coatings for Self-Cleaning and Antifogging. J. Mater. Chem. 2012, 22, 7420-7426

[84] Chen, Y, Zhang, Y, Shi, L, Li, J, Xin, Y, Yang, T, Guo, Z. Transparent Superhydrophobic/Superhydrophilic Coatings for Self-Cleaning and Anti-fogging. Appl. Phys. Lett. 2012, 101033701 